\title{
Subject Evaluation with Chinese Characteristics: Changes, Confusion and Outlet-Take China University Subject Rankings (CUSR) for an Example
}

\author{
Guotao Ma, Qinglin Jin*, Fei Ye \\ Development and Planning Office, Central University of Finance and Economics, Beijing, China \\ Email address: \\ maguotao@cufe.edu.cn (Guotao Ma), marykim@163.com (Qinglin Jin), yefei1030@126.com (Fei Ye) \\ ${ }^{*}$ Corresponding author
}

To cite this article:

Guotao Ma, Qinglin Jin, Fei Ye. Subject Evaluation with Chinese Characteristics: Changes, Confusion and Outlet-Take China University Subject Rankings (CUSR) for an Example. Higher Education Research. Vol. 5, No. 3, 2020, pp. 68-75. doi: 10.11648/j.her.20200503.11

Received: April 14, 2020; Accepted: April 30, 2020; Published: May 19, 2020

\begin{abstract}
The ranking of subjects is attracting more and more attention from the government, universities and society in China. As the most representative and credible subject evaluation in China, China University Subject Rankings (CUSR) has carried out four rounds since the first round in 2002. Its evaluation purpose, evaluation content, evaluation main body, evaluation indicators and the use of evaluation results have also been gradually developing, revising and adjusting, becoming more detailed, multi-dimensional and optimized. With the influence of the subject evaluation, the number of participating subjects, and social attention increasing, CUSR is faced with several practical problems of being alienated in the process of specific operation and application of results: the evaluation itself is regarded as the purpose; the nature of the evaluation is disputed; the appeal for the scientificity of the evaluation indicators is improved; and the evaluation result deviates from the original intention. In order to better meet the strategic needs of national development and the practical needs of university development, the optimization path of subject evaluation is to build Chinese characteristics and realize Sinification, continuously improve the scientificity and credibility, actively learn from international experience and expand international influence, so as to serve subject construction and development, and promote the overall improvement of the academic degrees and graduate education in China.
\end{abstract}

Keywords: Subject Evaluation, China University Subject Rankings (CUSR), Evolution Logic, Optimization Path

\section{Introduction}

The ranking of universities and subjects has always been a hot issue in the field of higher education worldwide. However, given the large differences in the scale and characteristics of colleges and universities, it is obvious that the ranking of subjects as an important indicator of the level and characteristics of colleges and universities is more and more aroused by the government, universities and society. At present, China is coordinating the promotion of the "Double First-Class" initiative. In the historical turning period of higher education in China, how to realize the goal of "accelerating the construction of First-Class universities and First-Class subjects to achieve the inclusive development of higher education " proposed by the 19th National Congress of the CPC while "rooting education in China's land" is extremely urgent, and China University Subject Rankings
(CUSR) as the most representative and credible evaluations organized by China Academic Degrees and Graduate Education Development Centre (CDGDC), the influence of the results on the government, universities, and society is self-evident. Because subject evaluation involves multi-dimensional interests, it is necessary to systematically summarize and discuss the actual dilemmas and proper choices, improve the subject evaluation system with Chinese characteristics, realize the localization of subject evaluation, promote the subject construction and the connotative development of higher education in China, build modern education with Chinese characteristics and world level.

\section{Evolution Logic of Subject Evaluation}

Since the founding of New China, especially since the restoration of the college entrance examination, the 
leap-forward development of Chinese higher education is the logical starting point of subject evaluation, especially in the process of higher education changing from elitism to popularization, and the process from domestic education to international education competition, whether it is to stimulate the vitality of subject construction in universities, ensure the quality of academic degrees and graduate education, or to meet the society 's need for information about universities and subjects, or to serve the decision-making of government education departments, we call for a subject evaluation to make relative credible evaluation. Subject evaluation should also become the "invisible hand" accordingly, and its evolution must serve the "visible hand" of national higher education orientation.

\subsection{Background and Development Process of CUSR}

In the early $1990 \mathrm{~s}$, with the rapid development of various national undertakings, the speed and scale of personnel training lags behind the needs of social development, and the contradiction between supply and demand for higher education talents has gradually become prominent. In 1999, the Ministry of Education announced the "Action Plan for Education Promotion for the 21st Century", colleges and universities began to expand enrollment on a large scale, and higher education moved from elitism to popularization [1].

In 2001, when China joined the World Trade Organization, China's higher education faced unprecedented impacts and challenges just as economic development. How to achieve high-quality and sustainable development? How to improve international competitiveness in the increasingly fierce competition? Subject evaluation came into being. In 2002, to serve the society and improve the subject construction of higher education overall in China, CDGDC tried to evaluate the level of subject construction of higher education institutions and research institutes combining the characteristics of subject development in China, based on the experience of developed countries in subject evaluation [2].
At present, CDGDC has carried out four rounds of evaluation in continuous exploration (Table 1). The indicator system for the first round of CUSR in 2002-2004 mainly refers to the condition indicators of the national degree authorization review. In other words, the subject evaluation at that time paid more attention to basic conditions, and the quantity was more evaluated compared with the quality. The evaluation results received some attention from the society, which also laid a certain foundation for the establishment of the later subject evaluation system; The indicator system for the second round of CUSR from 2006 to 2008 is guided by the health and sustainability of the subject, and more attention is paid to the indicators reflecting the level and quality of the subject. It is a further exploration based on the first round of evaluation, and the results have been obtained by the participating units and the public opinion; The third round of CUSR in 2012 clarified the purpose of serving the overall situation, schools, and society, and conducted a one-time evaluation of all subjects, further strengthened the evaluation of the level and quality of subject construction, and encouraged colleges and universities to promote connotative development. Secondary indicators such as "representative paper evaluation", "international exchange of students" and "excellent graduates" have been set for the first time. The evaluation results have received unprecedented attention and universal recognition from government departments, participating units and all sectors of society [2], the domestic credibility and international influence of the subject evaluation brand are gradually improved [3]; The fourth round of CUSR in 2016 revolved around the two central tasks of connotative development and improvement of quality of higher education. The indicator system was more categorized, which increased the consideration of colleges and universities serving the society, more in line with the strategic needs of national development, the practical needs of the development of colleges and universities, and the development trend of international higher education and evaluation.

Table 1. Comparison of Four Rounds of CUSR by CDGDC.

\begin{tabular}{|c|c|c|c|c|c|c|c|c|}
\hline \multirow[b]{2}{*}{ Round } & \multirow[b]{2}{*}{ Batch } & \multirow[b]{2}{*}{ Year } & \multirow[b]{2}{*}{$\begin{array}{l}\text { Number of } \\
\text { Subjects }\end{array}$} & \multirow[b]{2}{*}{$\begin{array}{l}\text { Number of } \\
\text { Universities and } \\
\text { Colleges Applied }\end{array}$} & \multirow[b]{2}{*}{$\begin{array}{l}\text { Number of } \\
\text { Subjects } \\
\text { Applied }\end{array}$} & \multicolumn{3}{|l|}{ Indicator System } \\
\hline & & & & & & First-Level Indicators (Number) & $\begin{array}{l}\text { Number of } \\
\text { Second-Level } \\
\text { Indicators } \\
\end{array}$ & $\begin{array}{l}\text { Number of } \\
\text { Third-Level } \\
\text { Indicators } \\
\end{array}$ \\
\hline \multirow{3}{*}{ 1st Round } & 1st Batch & 2002 & 12 & 89 & 309 & \multirow{5}{*}{$\begin{array}{l}\text { Academic team, scientific research, } \\
\text { personnel training, academic } \\
\text { reputation (4) } \\
\text { Academic team, scientific research, } \\
\text { personnel training, academic } \\
\text { reputation (4) }\end{array}$} & & \\
\hline & 2nd Batch & 2003 & 42 & 157 & 620 & & - & - \\
\hline & 3rd Batch & 2004 & 26 & 131 & 437 & & & \\
\hline \multirow[b]{3}{*}{ 3rd Round } & 1st Batch & 2006 & 31 & 193 & 1067 & & & \\
\hline & 2nd Batch & 2008 & 50 & 248 & 1302 & & 7 & 25 \\
\hline & - & 2012 & 95 & 391 & 4235 & $\begin{array}{l}\text { Faculty and resources, level of } \\
\text { scientific research, quality of } \\
\text { personnel training, discipline } \\
\text { reputation (4) }\end{array}$ & 16 & - \\
\hline 4th Round & - & 2016 & 95 & 513 & 7449 & $\begin{array}{l}\text { Faculty and resources, personnel } \\
\text { training quality, scientific research } \\
\text { level, social services and discipline } \\
\text { reputation (4) }\end{array}$ & $10-11$ & $15-18$ \\
\hline
\end{tabular}




\subsection{Characteristics and Trends of CUSR}

\subsubsection{Evaluation Purpose of Gradual Conversion}

When CDGDC just launched CUSR in 2002, it was clearly stated that the purpose is to develop a third-party education evaluation service independently for the central and local governments, all degree awarding units in China, and the domestic and international community [4], aiming to improve the quality of education, the academic level, besides the social understanding of colleges and universities. After the first three rounds of evaluation, these three major purposes are basically completed.

In 2015, with the promulgation of the "Overall Plan for Promoting the Construction of First-Class Universities and First-Class Subjects", the fourth round of evaluation was urgently needed to guide the government, universities and society to jointly build the "Double First-Class", the purpose of CUSR began to change to the national educational reform and development strategic goals of improving the level of higher education in China and enhancing the national core competitiveness.

\subsubsection{Evaluation Content of Classification Guidance}

At the beginning of CUSR, as school level and quality do not differ greatly among different types and levels of colleges and universities in China, the first and second rounds of evaluation could be operated in accordance with a unified evaluation plan, indicator system, and evaluation standards. In 2010, the "Outline of the National Medium and Long Term Education Reform and Development Plan" (2010-2020) proposed to "promote the characteristics of colleges and universities. Establish a college classification system and implement classification management." The indicator system of the third round of CUSR was set up on the basis of the original indicator framework according to the categories of "humanities and social sciences", "science, engineering, agriculture and medicine", "management", "art", "physical education and sport science", "architecture", and "computer". In 2015, the construction plan of "Double First-Class" initiative continued to make clear that it was required to guide and support colleges and universities to optimize the subject structure, consolidate the direction of subject development, create more subject peaks, and drive schools to play their advantages and develop characteristics. At the same time, colleges and universities should choose the construction path of whether First-Class University or First-Class Subject according to their own actual conditions, this puts forward a realistic need for the fourth round of evaluation. Therefore, the fourth round of CUSR began to propose the basic evaluation ideas of classification evaluation and guidance, the "humanities", "society", "science", "industry", "agriculture", "medicine" and other subjects were separately set up indicator systems to reflect the characteristics of subject and enhance the rationality and scientific nature of subject evaluation.

\subsubsection{Gradually Diversified Evaluation Main Body}

The past three rounds of evaluation were basically conducted under the leadership of CDGDC and had a certain "official color". Although some social forces had participated in the evaluation, the discourse weight was not large, which has affected the objectivity and fairness of the subject evaluation to a certain extent. In order to improve the social participation and enhance the credibility of subject evaluation, the fourth round of CUSR began to focus on subject evaluation stakeholders and adopted a variety of evaluation main bodies. For example, in the indicator of the quality of tutor guidance, students were recruited as the evaluation main body and were given a questionnaire survey to investigate the guidance of tutors; in the indicator of employer evaluation, graduates and employment units were the evaluation main bodies, the feedback of whom were to evaluate the professional competence, professional ethics, satisfaction of college graduates; in the indicator of subject reputation, experts in various fields were invited to evaluate the academic reputation and academic ethics of colleges and universities through multiple aspects, and gradually it has formed an evaluation main bodies' group integrating CDGDC, college students, social employers, and industry experts, which has improved the credibility of CUSR.

\subsubsection{Continuous Optimization of Evaluation Indicators}

As mentioned before, in the first three rounds of evaluation, due to the small differences in school running characteristics among colleges and universities, the form of evaluation indicator system was relatively simple and most were quantitative indicators, which caused the deviation of evaluation results to a certain extent, and all sectors of society also made different comments on subject evaluation. After the introduction of the overall plan for "Double First-Class" initiative, with the changes in the evaluation purpose and value orientation, CDGDC followed the guidance of "quality, effectiveness, characteristics, classification", further adjusted and optimized the evaluation indicator system [5]. It is embodied in: First, the combination of quality and quantitative indicators. For indicators such as number of full-time faculties, number of degrees awarded, quality of faculty, and outstanding students, the quality was highlighted by setting an "upper limit"; Second, the combination of process and result indicators. The emphasis is no longer on the "conditional resources" indicators, but on the "effects", "quality" and "characteristics" indicators, highlighting the achievements and effects of subject connotation construction; Third, the combination of subjective and objective indicators. For example, the evaluation of faculty's quality is changed from objective evaluation in the past to a combination of subjective and objective evaluation, and experts make a comprehensive evaluation of the level, structure, and internationalization of the faculty; Fourth, the combination of domestic and foreign academic achievements. For the indicator of academic papers' quality, not only the collection is evaluated, but also no less than 15 representative domestic papers were stipulated to include; Fifth, the combination of serving schools and serving society indicators. Not only the task of colleges and universities to improve the quality of education and the level of subjects is highlighted, but also the concept of subject 
construction serving the society is strengthened, and the contribution of subjects to promoting excellent culture and scientific development is evaluated. These optimization measures are the performance of subject evaluation to actively adapt to the new normal of higher education development [6].

\subsubsection{Multi-dimensional Evaluation Results}

The value of subject evaluation lies in the communication and reasonable use of the evaluation results [7]. As the most objective and most influential subject evaluation among domestic evaluation institutions, the evaluation results are often highly concerned by the government, universities, and social parties, and become an important reference for resource allocation.

In the first three rounds of CUSR, the main form of evaluation results was ranking, the top ranked subjects might be valued by the government and universities and concentrated on construction, while the lower ranked subjects might face the risk of being abolished. This ranking-oriented subject evaluation may result in many colleges only focusing on the achievement of immediate subject construction and ignoring long-term subject cultivation, placing too much emphasis on the rankings and ignoring the improvement of scientific research and talent training quality [4]. Faced with these problems, the fourth round of CUSR was more multi-dimensional and scientific in the way the evaluation results were published and utilized, its results were firstly sorted into "grades" by the percentile of the overall score, and released to the public the top $70 \%$ of each subject [8], using the clustering method to dilute the absolute ranking and guide colleges and universities to focus on subject construction and development. In addition, through the analysis of the data collected in the evaluation, it could help colleges and universities to carry out SWOT analysis of their subject construction and guide them to develop subjects scientifically and rationally, in this case, the deep utilization of evaluation results is strengthen.

\section{Real Confusions of Subject Evaluation}

Through four rounds of CUSR, it is found that CDGDC has conducted many rational explorations, corrections and adjustments in the aspect of process management, indicator system designing, and result publishing form. Especially with the influence of CUSR, the number of participating subjects, and social attention increasing, as an evaluation of Chinese characteristics, in order to provide diagnostic reference for the development of subjects and the construction of "Double First-Class" initiative, and to provide development momentum for the modernization of Chinese higher education, it is necessary for CUSR to solve the functional limitations of the evaluation itself, and to avoid external speculative behavior that depends on the evaluation results. Although the rationality of CUSR is obvious, there are real confusions of alienation in the process of specific operation and results application.

\subsection{Purpose: Self Improvement or Better Ranking}

Subject evaluation is an important means to promote the development of subjects. Judging from the trend of international higher education evaluation, many countries and universities have put more attention on finding problems and then correcting the development path and ensuring the quality of development. For government and society, subject evaluation serves their information needs of university subjects, provides a certain reference for government to make decisions on the development of higher education and a new channel for society to understand the quality of graduate education and the level of subject construction; for colleges and universities, it is widely used as an excellent management tool [9]. On the one hand, subject evaluation is an important part of the quality assurance system, it helps understanding the advantages and disadvantages, discovering the shortcomings and deficiencies, and finding problems in a targeted manner to promote the overall level of subject construction, through evaluating the effectiveness of subject construction and the quality of postgraduate training; on the other hand, it is also an important way for universities to optimize the layout and consolidate the characteristics of subjects, and is an important means to solve the problem of unbalanced and inadequate subject development. General Secretary Xi Jinping pointed out that it is necessary to support qualified colleges and universities to create First-Class, encourage colleges and universities to develop characteristics, and strive for First-Class in different subjects or different directions of the same subject. However, with the gradual expansion of the influence of CUSR, the spillover effect of evaluation results has gradually widened the gap in resource acquisition capabilities of different grade subjects. Colleges and universities are likely to reverse their understanding of the evaluation and regard it as its purpose, dwarfing it into a "vanity fair" and alienating the results into a "knock-kick" for obtaining government and social resources, which may breed the rationality crisis of subject evaluation: in order to achieve the ideal results in subject evaluation and get the recognition of government and society for further access to various resources, some colleges and universities often graft and assemble the achievements of subject, which cannot truly reflect the actual situation of the subject under evaluation, resulting in the deviation between the construction effect and evaluation result.

\subsection{Nature: Official or Third Party}

The "Thirteenth Five-Year Plan for National Education Development" proposed that by 2020, "basically achieve separation of management and evaluation, form a pattern of government management according to law, schools running independently according to law, and all sectors of society participating and supervising according to law, modernization level of education governance system and governance capacity has been significantly improved". It can be seen that the separation of management and evaluation is an important means and sign of a significant improvement in the level of 
modernization of the education governance system and governance capacity. For higher education, it is not controversial that the government is responsible for "management" and universities are responsible for "running", but does it mean that the third party is responsible for "evaluation"? This is an open question. It can be "evaluated" by a third party, or by government the subject of the "management", which means that the subject of "evaluation" can be diverse, for example, in 2016, the Office of National Education Inspection commissioned CDGDC to organize the China University Professional-degree Rankings (CUPR) in the form of a third party, it was the government's "evaluation", CDGDC was commissioned to organize it due to the professionalism and complexity of evaluation. Specific to CUSR, from the perspective of its implementation subject, CDGDC has always emphasized its third-party attribute, that is, CUSR is "a non-administrative and service evaluation program organized by a third party" [8]. However, from the perspective of universities and society, it has not been completely regarded as a third-party evaluation equivalent to the Times Higher Education World University Rankings (THE) or QS World University Ranking, because first of all, CDGDC is an administrative department directly under the Ministry of Education, and its functions include "providing counseling for the Ministry of Education (MoE) and the Academic Degrees Committee of the State Council (ADCSC) in formulating policies concerned", and "undertaking the task of evaluating and appraising the academic degrees and graduate education, entrusted by MoE and ADCSC. And when necessary, CDGDC has the authority to independently conduct the similar tasks entrusted by any social establishments" [10]. Therefore, the evaluation results are even used as a reference for some provincial local governments to make resource investments, and as an important basis for some universities to formulate subject development plans, adjust subject construction layout, and optimize subject resource allocation, and are widely considered to be closely related to the "Double First-Class" initiative. Although different from the official attributes of the above-mentioned CUPR, it cannot be arbitrarily emphasized whether CUSR is official or third-party. In any case, CUSR is a milestone progress in the history of higher education in China, because "Project 211" and "Project 985" are both government-designated and immutable, but the results of subject evaluation are dynamic and can relatively reflect the development of various subjects of colleges and universities in China.

\subsection{Indicator System: Classified or Unified}

Subject evaluation is neither an evaluation of the overall development level of a university, nor an evaluation of the position of each subject in a university, but a horizontal evaluation of the same subject in each university, so there is no compatibility problem between different subjects in the actual evaluation.

Different indicator systems can be designed for each subject on the basis of common laws, taking full account of the interdisciplinary, openness and uniqueness, so that different subjects can find gaps and deficiencies according to their own rules, so as to promote reform by evaluation and construction by reform, and promote the overall improvement of the construction level of the same subjects. It is precisely because of taking into account the differences in the content among various subjects, each round of subject evaluation has improved from the previous round in evaluation indicator system, for example, compared with the third round, the fourth round of subject evaluation indicator system has been expanded from seven categories to nine categories, and individualized "social service contribution" and other indicators have been added. However, subjects as the complex systems of knowledge formed in the process of human understanding of the objective world, the research objects and research methods are different, and the different research directions are more complicated, although the indicator systems are divided into nine categories, in essence, regardless of whether it is the subject of literature, history and philosophy, science and engineering, or physical education, the same second-level and even third-level indicator system frameworks are basically adopted. The "Unified" problem is not well solved. The argument about the nature of subject evaluation can be attributed to the discussion of objectivity and neutrality of subject evaluation.

\subsection{Impact: Catfish Effect or the Matthew Effect}

Subject evaluation is to some extent helpful to urge colleges and universities to pay more attention to subject construction. In the fourth round of CUSR, the subject binding evaluation principle and subject excellence rate rule were set up, which were intended to prevent the achievements from being pieced together, and promote the universities to liberate from the extensional development mode which only pursues scale, and accelerate the connotative development. Subject evaluation could have played the "Catfish Effect" through a negative incentives, that is, to stimulate the development vitality of non-advantaged subjects through the advantages of other subjects in the university and the same subjects in other universities, so that the development of non-advantaged subjects could be accelerated.

But in the actual process, colleges and universities tend to focus on subjects of grade $\mathrm{B}+$ and above, especially grade $\mathrm{A}+$ for the top $2 \%$, because subjects of $A$ grades (including grade $\mathrm{A}+, \mathrm{A}, \mathrm{A}-)$ are excellent subjects, and subjects of grade $\mathrm{B}+$ have the potential to further develop into A grades. These subjects are at the top of the university's resource allocation pyramid, and with a lot of resources invested, will still achieve ideal results in the next round of subject evaluation, becoming the beneficiary of the "Matthew Effect". However, other subjects of B or C grades or those even not in the top $70 \%$ ones are hardly given priority to, and may even be revoked, becoming the object of dynamic adjustment in the so-called optimized subject layout. This kind of phenomenon which only focuses on and vigorously develops subjects of grade B+ and above (top 20\%) and ignores other subjects has seriously damaged the academic ecology of colleges and universities, the seemingly optimized subject layout is actually not 
conducive to the long-term development and violates the original intention of subject evaluation.

\section{Optimization Path of Subject Evaluation}

The development of everything is the result of internal and external factors. To subjects, the different development and evolution rules are the internal development logic that promotes self-optimization, while the strong support of the country, university and society, and the rational allocation of people, finance, and material constitute the external development logic that promotes development. Obviously, as an "instrument panel" for the achievements of subject construction, subject evaluation has multiple missions, it is necessary to follow the internal rules of subject development and the basic rules of national higher education development in system designing, so as to provide a pulse for the subject development and promote the connotation development of higher education; and also to take into account the policy guidance of education authorities in a specific period and guide subjects to meet the needs. Compared with the strong education countries in Europe and America, the development of subject evaluation with Chinese characteristics has no experience to copy, and must be Sinicized. Subject evaluation can only achieve development in reflecting the times and nationality, and solve Chinese problems with Chinese solutions, and then have international influence.

\subsection{Adhere to "Four Self-Confidences", Highlight Chinese Characteristics and Serve the Needs of China}

To evaluate by classification and negotiate by multi-parties. The higher the pertinence and scientificity of the subject evaluation indicator system, the higher the awareness and participation of stakeholders in subject evaluation, the stronger the credibility of subject evaluation. First, there are great differences between different subjects. Even if they are in the same subject area, it should be avoided to cut at one stroke. For example, there are great differences between psychology and physical education and sport science under the subject area of education; theoretical Economics and applied Economics under the subject area of economics are another example. The indicator system should be further refined and classified according to the characteristics of different subjects, with weightings of indicators that effectively reflect the characteristics of subjects be increased. Second, in consideration of the recognition of all parties on the importance of subject evaluation results, learn from other influential third-party evaluations, it is advisable to publish each component's evaluation results, such as talent training or social services, so as to highlight advantages and characteristics. Third, since the subject evaluation involves multiple interests, the government should strengthen rather than weaken the guidance to ensure the policy orientation of subject evaluation. As the organizer, CDGDC should fully respect the voice of universities and experts, especially respect for the role of professional organizations such as subject consultative groups of ADCSC, through argumentation and consultation, the scientificity and legitimacy of evaluation will be improved, and the evaluation process will be open to the public, so as to make the subject evaluation transparent.

To Highlight the characteristics and serve the needs. Subject evaluation is an evaluation for Chinese universities, and should be based on China's national conditions, reflecting Chinese characteristics and serving China's development. First, Marxism is the brightest background of Chinese colleges and universities, and establishing moral integrity in cultivation is the fundamental task, "moral education" is the first and should be placed in the core position when evaluating the process and quality of talent training. Second, teaching staff is the key to building high-level colleges and universities, when evaluating the professional skills such as "professional knowledge, education level, teaching method", it should be profound understanding that faculties' moral and style is the first criterion for quality evaluation, and "political qualities" should be strengthened; Third, subject construction is ultimately to serve the country's technological progress and economic and social development. Therefore, in the selection of evaluation indicators, it should be insisting on taking root in China and considering the ability of a subject to serve the country's major strategies, economic and social development, and regional needs. For example, the evaluation of humanities and social sciences should focus on how to embody "inheritance and nationality", "originality and timeliness", and evaluate its contribution to building the school of philosophy and social sciences with Chinese characteristics and Chinese style; the evaluation of science and technology should focus on what major breakthroughs have been made in theory, and what key problems have been technically solved.

\subsection{Adhere to "Coordinated Development", Form Scientific Guide and Rebuild Sustainable Ecology}

Subject development has its own development law, and following the law is the prerequisite for perfecting the subject evaluation system with Chinese characteristics, only under this premise can it be meaningful to discuss the sustainable development ecology of subjects, therefore, the subject evaluation should be more suitable for the subject construction law itself, that is, in line with its internal development logic. At the same time, the subject evaluation should reflect the mission of Chinese higher education in a true and objective manner, and be adjusted in time with the development and changes of Chinese higher education, that is, "Sinification". As the subject evaluation has a role as a "baton" to a certain extent, its orientation is particularly important. Therefore, in the evaluation process, the following relationships should be handled to promote coordinated development: First, the relationship between teaching and scientific research. Although the weightings of talent training in the previous evaluations has been continuously strengthened, the indicators of academic titles and major projects in the subject are still explicit and valued, while teaching seems to be implicit and despised, and the competition for faculties is generally based 
on scientific research capacity rather than teaching capacity. How to give more prominence to the core position of talent training and realize the differential coexistence of teaching and scientific research still needs to be considered. Second, the relationship between advantaged and non-advantaged subjects. The fourth round of CUSR put forward the concept of "subject excellence rate", guiding colleges and universities to optimize the layout of subjects and promote connotative development so that to solve the problem of unbalanced and insufficient development of subjects. However, in order to obtain a high subject excellence rate, some universities withdrew non-advantaged subjects, resulting in the destruction of the subject ecology. The spirit of colleges and universities is inseparable from multidisciplinary nourishment The humanities is conducive to nourishing speculative and critical thinking, while natural sciences nourishing rational and scientific thinking, and so on. Non-advantaged and advantaged subjects should jointly promote the all-round development of people (including faculties and students), promote interdisciplinary integration and form new growth points, rather than a relationship between one and the other. Therefore, it should be avoided to blindly chop short boards from the guidance, but complement them and promote the overall improvement of the subject construction level. Third, the relationship between localization and internationalization. Subject evaluation is an evaluation for Chinese universities, which is rooted in China, therefore, Chinese standards should be reflected in the design of indicators. For example, the fourth round of CUSR stipulated the upper limit of representative foreign papers and strengthened the important role of Chinese journals, research achievements reflect nationality and times are encouraged. However, Chinese standards do not mean self-talk and blind self-confidence, it is also necessary to increase the international influence of Chinese higher education by participating in international higher education competition and provide China's plans and experiences for international higher education, and to solve the problem of "voice in the world is still relatively small, and still in a situation where cannot speak and cannot spread" especially in the area of philosophy and social sciences [11].

\subsection{Adhere to "Inclusive", Learn from International Experience and Enhance International Influence}

Whether recognized or not, CUSR has a more or less government background, its organizer CDGDC is an administrative department directly under the Ministry of Education, and the evaluation results are used by some local governments as a reference indicator for resource allocation, this doesn't mean it's unreasonable, the debate about its attribute is official or third-party does not make much sense, the key point is to play a positive role in subject construction, so any copy of foreign influential third-party evaluation is not necessarily wise, and is hardly feasible. However, it is not to say that there is no intersection between subject assessment and other assessments, and we should actively learn from international experience and conform to the trend of international assessment. In particular, the latest progress or achievements in assessment concepts and assessment techniques can be used for reference and absorption by us [12] At the same time, the premise of leading is dialogue. In order to enhance the influence of Chinese higher education and the popularity of China's First-Class subjects, overseas peer experts should be further invited to participate in reputation surveys, so that to expand international influence and explore experiences for internationalization of subjects and subject evaluation of China.

\section{Conclusion}

Chinese higher education is in the historical turning period from great to strong. We should not only work hard on the ground, but also recognize the situation and target. In this process, subject evaluation and its results naturally play an important role. Scientific evaluation will produce a positive direction and become a booster for the development of Chinese higher education. This requires that China's education industry continuously improve the cognition of subject evaluation, correctly shape the evaluation, correctly participate in the evaluation, and correctly recognize and treat the evaluation.

\section{References}

[1] Yi Jidong, Zhang Shaozong and Tie Faxian. Theory and practice of higher education evaluation. Beijing: Science Press, 2009.

[2] Wang Lisheng, Lin Mengquan, Ren Chao and Chen Yan (2016) The development and reform of subject evaluation in China. China Higher Education, 21: 38-41.

[3] Lin Mengquan, Jiang Hui and Ren Chao (2010). The development and reform of subject evaluation. China Higher Education, 21: 43-44.

[4] Zhang Jiping and Huang Qin (2017). Ten major value orientation changes in discipline evaluation in the context of "Double First-class" construction. Journal of graduation education, 6: 75-82.

[5] Peng Qinglong (2016). Research on the new trend of discipline ranking and the new path of the quality-oriented discipline construction of foreign languages and literature. Foreign Language World, 3: 34-41.

[6] Zhang Liwei and Guo Wei (2017). Building a world-class education evaluation brand with Chinese characteristics-An interview with Wang Lisheng, the director of China Academic Degrees and Graduate Education Development Centre (CDGDC). Journal of world education, 8: 8-13.

[7] Zhao Liying (2018). Accountability and improvement: the meta evaluation of the fourth round of subject evaluation in China. Academic Degrees \& Graduate Education, 2: 32-38.

[8] China Academic Degrees and Graduate Education Development Centre, A brief introduction of the fourth round of China University Subject Rankings (CUSR), http://www.chinadegrees.cn/xwyyjsjyxx/xkpgjg/2016phden/in dex.shtml. 
[9] Niu Junxia and Dong Zefang (2018). The discipline assessment serves for "Double First-class" construction: ideas, obstacles and ways. Education science, 6: 65-70.

[10] China Academic Degrees and Graduate Education Development Centre, Introduction of China Academic Degrees and Graduate Education Development Centre, http://www.chinadegrees.cn/xwyyjsjyxx/gywm/zxjj/277079.sh tml.
[11] President Xi's speech at Working Forum of philosophy and social sciences, http://www.xinhuanet.com//politics/2016-05/18/c_111889112 8.htm.

[12] Xie Debo and Li Xiaoying (2019). An optimized path of the discipline assessment system with Chinese characteristics: Based on the analysis of some problems in the fourth round of discipline evaluation. Journal of Xiamen University (Arts \& Social Sciences), 1: 100-107. 